\title{
The Perceptions of Community Change through Promoting Positive Sexual Health: A Teenage Pregnancy Program Evaluation
}

\author{
Quynh Lế $\hat{e}^{1, *}$, Stuart Auckland ${ }^{1}$, Hoang Boi Nguyen ${ }^{1}$, Daniel R Terry ${ }^{2}$ \\ ${ }^{1}$ Centre for Rural Health, University of Tasmania, Australia \\ ${ }^{2}$ Department of Rural Health, Melbourne Medical School, The University of Melbourne, Australia
}

Copyright $@ 2015$ Horizon Research Publishing All rights reserved.

\begin{abstract}
Teenage pregnancy is associated with adverse social, economic and health outcomes for both mother and child. The factors frequently associated with teenage pregnancy or related sexual health issues include teenagers' knowledge, attitudes, and beliefs about sex and other social-economic factors such as levels of poverty, academic success or failure, and parents' education. This paper reports on the evaluation of a teenage pregnancy program conducted in the Southern and North Western regions of Tasmania to address the high levels of teenage pregnancy and sexually transmitted infection (STIs) in these regions. The aim of the study was to examine the effectiveness of the Teenage Pregnancy Programs by examining any evidence for a community change in attitudes and behaviours, and any changes in youth awareness about sexual health. The study adopted a qualitative approach and data were collected from a total of 25 participants ( 17 who were interviewed and eight who participated in focus groups) residing in the target regions. Data were analysed using thematic analysis using Nvivo 9.0. The study results indicated that the program was well managed and delivered. There were reported changes in the awareness, attitudes and behaviours regarding sexual health within the target communities, which were considered necessary for young people to make well informed choices. The evaluation of the program provides valuable knowledge regarding the processes and outcomes that may have application in future community based sexual health initiatives may be delivered into regional communities.
\end{abstract}

Keywords Teen Pregnancy, Sexual Health, Socioeconomic Disadvantage, Behavioural Change, Community-based Interventions

\section{Introduction}

Governments and researchers nationally and internationally have put great efforts into developing and implementing appropriate programs to reduce the rates of unplanned pregnancy among teenagers. [1-6] They have tried to increase understanding of the social lives, contexts, needs, and behaviours of teenagers. At the same time, they have prioritised prevention or intervention programs to minimise the risk factors that increase the likelihood of teenagers becoming pregnant and to maximise the protective factors that decrease this likelihood. [7]

Darroch and colleagues [8] highlighted three key factors which determined higher pregnancy and STI rates: the age at sexual debut; the level of condom or contraceptive use, and attitudes regarding their use; and the number of sexual partners. In the study, Darroch and colleagues [8] showed those who were younger, did not have access to or understanding of contraception use and those with more than two sexual partners within a given time were at higher risk of STIs and pregnancy. [8-10] Other factors that contribute to unintended adolescent pregnancy include: a level of ambivalence, low social support, low expectations, poor employment and education opportunities as well as other social factors. $[8,11]$

Over the past five decades there has been much research and a variety of studies that have evaluated, reviewed and analysed teen sexual health and preventative teen pregnancy programs and strategies. [12-25] However, Brindis and colleagues [7] within their study, identified three fundamental pillars necessary for successful intervention programs on teenage pregnancy: family life education; contraceptive services; and youth development and life options. Similarly, in his comprehensive review on teenage pregnancy effectiveness research, Fullerton [12] outlined three main approaches: provision of sex education; provision of contraceptive services and counselling; and good general education/vocational programmes, each with details about the goals in promoting positive sexual health and preventing pregnancy and STIs. Both models take a holistic and multi-component approach in identifying the critical predictors of successful community based prevention/intervention sexual health programs. 
According to Scher and colleagues [26], multi-component youth development programs have had the most impact and this model has been embraced globally. Reflecting teenagers' social and environmental context, community-based interventions, are believed to be underpinned by social norms that sustain protective behaviours and promote individual behaviours that reduce pregnancy risks. [7]

In Australia multi-component and community-based participatory approaches are the most prevalent interventions. "Tell Me About It" is a typical project of this type, which involved collaborations between the group members and local communities in Wagga Wagga, New South Wales, in all processes of project development and implementation. [27] This project was considered to be cost-effective and sustainable in terms of community capacity building, network development and awareness raising. [27]

\subsection{The Current Challenge}

Tasmania is a small island state off the south east coast of mainland Australia with population over $n=500,000$. [28] Whilst the rates of teenage pregnancy have been falling in Tasmania, from 25.7 per 1,000 teenagers aged $15-19$ in 2000 , to 21.5 per 1,000 in 2010 , the general rate is well above the national teenage fertility rate of 15.5 births per 1,000 teenagers aged 15-19. [29] In addition, the rates of Chlamydia infection in Tasmania are relatively higher than in most other Australian states with prevalence amongst 15-24 year olds being well above the national average. [30]

The statistics on teenage birth rates show a variance in rates according to location and socio-economic disadvantage. $[8,11]$ A clear gradation exists from urban areas (particularly affluent urban areas) to remote and regional areas, with the highest teenage birth rates in areas of high socio-economic disadvantage. [29] For example, teenage pregnancy is particularly high in the lower socio-economic areas of the State such as the Derwent Valley and Burnie.[8]

The Derwent Valley Local Government Area is predominantly rural and has a total population of 9,708, of which $16.1 \%$ is aged 12-24. [31] The main town and service-centre for the Local Government Area is the rural township of New Norfolk. The Derwent Valley Local Government Area ranks within the bottom $20 \%$ of areas by Index of Relative Socio-economic Disadvantage (Decile 2) which equates to the fifth highest level of disadvantage when compared to the remaining 28 Local Government Areas in Tasmania. [32]

In contrast, the Burnie Local Government Area has a population of 19,892 , of which $16.9 \%$ of the population is aged 12 - 24. Burnie has an Index of Relative Socio-economic Disadvantage score within the third Decile, which equates to the tenth highest level of disadvantage when compared to the remaining 28 local government areas in Tasmania. [32]

\subsection{A solution}

In 2012, Family Planning Tasmania trialled multi-component and community-based Teenage Pregnancy Programs at two rural and regional sites in Tasmania. These sites included the southern Teenage Pregnancy Program which was based at New Norfolk in the Derwent Valley (south Tasmania), while the second site was the North West Teenage Pregnancy Program centred in the Local Government Area of Burnie (Burnie is the service centre for the NW region of Tasmania); however, it did include stakeholders and services within the rural Local Government Areas of Circular Head and Waratah/Wynyard.

The Teenage Pregnancy Programs adopted a 12-month innovative and integrative approach towards reducing teenage pregnancy. Rather than the solution being "owned" by government or schools, the responsibility for addressing this problem was seen as residing in the community, with Family Planning Tasmania providing leadership and guidance. Reflective of teenagers' social and environmental context, community-based interventions like these two programs, are believed to be underpinned by social norms that sustain protective behaviours and promote individual behaviours that reduce pregnancy risks. [7]

The evidence-based educational and clinical services were tailored specifically for the community, so that they can address the high rates of teen pregnancy in the regions. The aim of the programs was to foster significant changes in attitudes to teenage sexual and reproductive health, providing teens with knowledge, skills and advice on contraception. This was achieved by providing relationship, sexuality and peer counselling and education, while running relationship, sexuality and sexual health promotion activities in local communities. An outreach sexual and reproductive health clinic was provided once a fortnight to improve young people's access to contraception, STI screening and treatment. Lastly, training was provided for GPs with up-to-date information about sexuality, fertility and contraception, while professional development was provided for youth workers and health workers.

Specifically in the Derwent Valley, the Families and Schools Together (FAST) model was also implemented due to its workability and adaptability to local needs, particularly when addressing social issues such as teenage pregnancy. FAST has been developed and widely used as an effective educational approach since 1988. [33, 34] In principle, the FAST model aims to educate and change habits by bringing young people, their carers, families, schools, and communities together. This model can be adapted to improve knowledge and change attitudes and behaviours related to decision making, self-confidence, self-esteem, self-belief, open communication and to support a mechanism for sexual health related matters. [35] Community members, especially the young, gain essential knowledge and skills which help them become more effective peer educators within the host community. [33, 34]

The two programs address a number of the contributing 
factors of high rates of teen pregnancy and parenting. This included a lack of education, community support and accessibility regarding options for adoption and termination and for pregnant teens. It addressed a lack of awareness among young people and parents about potential negative outcomes of teen pregnancy and parenting. Lastly, the programs addressed the lack of role models for young women and mentored young women who experience social isolation and low self-esteem. The programs were characterised by a well-coordinated prevention approaches which may lead to the development of inclusive and viable solutions that are more specifically tailored to the unique needs of teenagers and the available resources within the community.

Young people (aged 14-19), both male and female, were engaged as peer educators, and community organisations as agents of change, to implement activities that have been shown to have reduced teen pregnancy rates nationally and internationally. Family Planning Tasmania provided expert guidance, tailoring its evidence-based educational and clinical services so that the communities could address the high rates of teen pregnancy in their own regions.

The ultimate aims of the Teenage Pregnancy Programs were to foster significant changes in attitudes to teenage sexual and reproductive health, providing teens with knowledge, skills and contraception. Some examples of practical activities were:

- Providing relationships and sexuality education including peer education programs through local community groups; and relationships, sexuality and sexual health promotion activities in local communities.

- Providing an outreach sexual and reproductive health clinic, providing a doctor in each region once a fortnight, to improve young people's access to contraception and STI screening and treatment.

- Providing training for GPs with up-to-date information about sexuality, fertility and contraception; and professional development for youth workers and health workers.

The two programs sought to address a number of the factors that contribute to high rates of teen pregnancy and parenting. Young people were engaged as peer educators, and community organisations as agents of change, to implement activities that addressed the factors that contribute to teenage pregnancy: (1) lack of education and community support; (2) lack of awareness among young people and parents about potential negative outcomes of teen pregnancy and parenting; and (3) lack of role models or mentors for young women who experience social isolation and low self-esteem. The Teenage Pregnancy Programs were designed to lead to the development of inclusive and viable solutions that are more specifically tailored to the specific and unique needs of teenagers within their communities.

The principle aim of this study is to examine the effectiveness of the Teenage Pregnancy Programs by examining any evidence for a community change in attitudes and behaviours, and any changes in youth awareness about sexual health, arising from the Teenage Pregnancy Programs.

\section{Methods}

\subsection{Research Approach}

The evaluation study adopted a qualitative approach. The use of focus group discussions and interviews to collect qualitative research evidence as rationale was that qualitative information could provide a deep and illuminating understanding of the community changes that might result from the Family Planning Teen Pregnancy program. Given the complex and multi-dimensional nature of the social phenomenon of teenage pregnancy, a focus was placed on the richness and depth rather than the breath of the collected information. [36-38] The strengths of qualitative methods is its capacity to provide representations of good quality research which are believable from the point of view of the research subjects rather than the researcher. [39] As qualitative data focuses on insights, meanings and the experiences of the research participants, the sample size is not always large, but is determined when new themes are no longer being provided or additional information is not being further generated. [36-38]

In addition, a qualitative approach was used primarily due to the importance of involving young people as research subjects rather than relying solely on the input from program staff and stakeholders. In addition, the nature of the study, that required a more direct model of engagement which would help ensure that the young participants' perspectives and attitudes were gathered and reported as accurately as possible. The decision to adopt a qualitative rather than a quantitative approach was also based on the understanding that there were a range of socio-economic issues such as access and literacy issues that may negatively impact on participation rates.

\subsection{Data Collection}

Within this research, research participants were recruited via contacts through Family Planning Tasmania for their participation either in a focus group discussion or interview. An invitation letter which introduced the researchers, the evaluation study, the purpose of the study and an information sheet, were sent to the Family Planning program coordinators located in New Norfolk and Burnie. The coordinators agreed to participate in the study both as participants and support staff in the recruitment of young persons as participants.

A total of 25 participants were either interviewed $(n=17)$ or participated in a focus group $(\mathrm{n}=8)$ at the two evaluation sites. Adults and teenager focus groups were conducted 
separately. The participants included six teenagers (aged 14-19) who participated in the health promotion activities and peer education program at either of the two study sites; three health professionals, who participated in the training courses which were conducted by Family Planning Tasmania ; thirteen stakeholders at the two study sites who were members of the Local Action Groups (LAGs) of the two programs; and three Family Planning Tasmania staff members who were directly involved in the management of the two programs.

Each interview or focus group was between 30 and 90 minutes and was audio recorded with the permission of each participant. All participants were invited to provide feedback on their views of the effectiveness and impact of the programs, with particular reference to: (1) the management and delivery of training, health promotion activities and peer education programs that target teens as well as their families and the general communities; and (2) the changes in awareness, attitudes, and behaviours among the young people as a result of the programs (Appendix 1).

\subsection{Data Analysis}

The interview and focus group data was subsequently transcribed into a Microsoft Word document with each the interview and focus group participants coded according to the order in which they were interviewed or voiced their views in the discussion. For example, the LAG members were coded as LAG1, LAG2, etc. The data were then imported to NVivo 9.0 software used for data collation. Data were then thematically analysed to systematically to identify key patterns and trends in the data and to compare expressed views. A number of quotations are included in the paper to illustrate and support the accounts emerging from the textual responses.

\section{Results}

A number of themes from the interviews and focus groups were identified which directly address the objectives of the evaluation: the stakeholder's and young people's perceptions of the outcomes (awareness enhancement, and community change in attitudes and behaviours); and process (management and delivery), of the two Teenage Pregnancy Programs.

\subsection{Indications of Changes among the Youth and the Community}

\subsubsection{Enhanced Awareness}

Speaking as the target population, most of the young participants felt positive about the programs which had recently been implemented, or were currently being implemented, in their areas. They especially emphasised the usefulness and relevance of the programs.

I didn't think I was going to learn so much about sexual health. I didn't even know what contraception was, but I do now. (Young person 2)

They don't tell you how you can get pregnant. They don't say how serious things are at school, like the STIs and things like that. And here you know more about it. It gave you a lot more information about what you should know and stuff like that. (Young person 3)

The nature of the programs was also seen as informative. There was an appreciation of the knowledge provided by health professionals and other stakeholders in the programs, which helped enrich their understanding about the issues of sexuality, fertility and contraception.

\subsubsection{Attitudinal and Behavioural Changes}

The project team and participants recognised that to measure attitude and behavioural change would be difficult within the limited timeframe of 12 months to undertake the Teenage Pregnancy Program intervention. Nevertheless there was a belief that the programs have led to an increased awareness and knowledge amongst the youth and young people within the two regions. Many young people praised the programs for the creation of a support network where communication opportunities, trust and understanding could be established between young people or young parents in similar circumstances. This included attitudes and communication skills related to sexual health, which were considered necessary for young people to make well informed choices.

This increased awareness and understanding about sexual health was understood to have influenced attitudinal change in the young participants. The interviewed participants stated that their attitudes had changed since being involved in the programs, shifting from being relaxed to being more conscientious about sexual health matters. This attitudinal change was evident in the following comment from a young participant.

I didn't care about who I did it with and I didn't have any responsibilities, but now from this it has made me think more about the stuff like pregnancies... it is a big deal. (Young person 1)

Likewise, the stakeholder participants also indicated that they were confident that attitudinal and behavioural changes had occurred amongst young people as a result of the programs. "It has created community awareness which creates more activity" (LAG2). Certain changes were more easily observed, such as more relaxed discussions and conversations around sexual health topics; an increase in the disseminations of related videos online to promote safe sex; and an increase in the number of visits to family planning centres.

As it is about changing attitude it is massive and a very slow process... it doesn't happen in a 12 month project ... but it has definitely started those conversations and awareness. (LAG4)

The stakeholders acknowledged the limited timeframe of 
the programs and that any community change would not initially be significant.

It was strongly believed that groups involved in program activities could impact others through changes in their own attitudes, awareness and behaviour, and this would help spread the key messages of the programs. Other groups in the communities, not only the target young population, were reported to have shown signs of attitudinal and behavioural change. For example, service providers and other organisations were being more attentive about how to bring about a positive change to the community.

Despite this, stakeholders discussed community change using the future tense. "We can only really speak in terms of what we expect." (Family planning service provider 1) This indicated that they were expecting the benefits from the programs to be more evident in the longer term rather than the immediate term, especially when many of the activities were still in progress.

\subsection{Strengths of Program Management and Delivery}

The perceptions of the participants regarding the effectiveness of the Teenage Pregnancy Programs design, management and delivery indicate six key strengths of the programs:

\subsubsection{Flexibility of Management and Coordination}

Positive comments were focussed on rather than having senior Family Planning Tasmania management impose a rigid program structure for the local stakeholder to implement, local stakeholders contributed to the shaping and refining of the programs.

I think we have made a great start and the program is open ended enough to get some really good conversations happening and it is a really good snapshot of our community of some really knowledgeable people, in terms of the local action group. (LAG6)

\subsubsection{Proactive Facilitators and Coordinators}

Another strong element was the proactive approach of the program coordinators and support facilitators. Specifically, they were depicted as being very active in approaching, inspiring, involving and connecting people. Their enthusiasm in coordinating program activities was believed to have positively influenced people and made program activities happen. It was their active performance that was believed to determine the success of the whole project.

The project officer now is very hands on, very active and not afraid to ask for help and go out and make something happen. (LAG4)

\subsubsection{Diversity in Approaches and Contents}

The effectiveness of the program delivery was due to approaches and the richness of the information covered.
Programs were accessible and reached a large number of community participants and the program design was developed to meet the needs of the local area. Through diverse activities, a wealth of information was conveyed to the community at different levels and in various ways. Information that was presented included knowledge, not only about sexual health and pregnancy, but also about the available services and the underpinning factors that might affect young people's choices.

\subsubsection{Collaboration of Different Organisations}

Collaboration was a large part of the process that developed and delivered the programs. Stakeholder participants stressed the value in exchanging ideas, resources and knowledge, as it contributed to the continued momentum of the programs. In addition the strength was observed in its wide diversity of organisations and it was believed to have prompted the introduction of innovative methods of program delivery.

That you had a lot of people in the NW that were really passionate about it, that the number of other services and providers, youth workers and things were keen to come on board was just fabulous ... So a great team. (Health care provider 3 )

\subsubsection{Community Involvement and Community Support}

Another frequently discussed strength of the programs was the high level of community involvement and community support. As a stakeholder noted, "... it is community based. That is a very big strength." (LAG2) In the view of the stakeholders, the involvement of the community in running the programs created a number of advantages in maximising the desired outcomes. An example of this community based approach was the sexual health peer education and communication program that was based on the FAST model. This approach was successful in attracting the support of the community with a lot of advocacy and commitment from community members.

I hit the ground running and met some amazing people, friends from this centre, child and family centre ... there are amazing people who are really committed to it and the project itself.. I've met some real movers and shakers that are young... they are absolutely inspiring. (Family planning service provider 1)

\subsubsection{Evidence-based and Need-based Approach}

The other strength of the programs was the ability to target community need while using evidence-based activities. For example, the Teenage Pregnancy Programs were successful as they were aimed at addressing and accommodating the real needs of the community. Program activities in the Derwent Valley had evolved from a need-analysis survey conducted by Family Planning Tasmania with resident grade nine students and youth 
groups to identify the gaps to fill, and which methods to employ. The evidence- and needs-based nature of the programs was regarded as strengths as they contributed to ensuring the appropriateness and validity of the overall programs.

\subsection{Limitations and Suggestions for Future Program Delivery}

Despite the predominantly positive comments, the participants also acknowledged the shortcomings of the programs and offered suggestions on how to improve future educational programs. Five leading concerns were made:

\subsubsection{Limited Time Frame}

The limited time frame for the programs emerged as a major concern. The issue of insufficient time echoed throughout the interviews and focus groups. "The short term nature is clearly a weakness." (LAG8). While the programs had ambitious aims in effecting community change, this was considered by the stakeholders to be impossible to achieve within a 12 -month period of time. For this reason, the stakeholders were concerned about how to accurately evaluate the community change as a result of their programs. This absence of immediate measurable outcomes was believed to leave everyone uncertain of the impact of the programs. In addition, due to the short time frame, many planned program activities had to be excluded. There was some anxiety among the stakeholders about the program deadline while certain activities were still very much in the planning phase.

\subsubsection{Limited Resources}

The lack of resources, such as human resources and infrastructure, was considered as another weak element of the programs. Of particular concern was the shortage of staff to fully dedicate to the programs. This was particularly a concern for the LAG members who had other responsibilities and could not devote sufficient time and energy to the programs. Some stakeholders expressed their concern that "once our funding runs out, then I think that will be the end of tackling that issue. It might be put back into a box and it won't be mentioned again, which is sad." (LAG1)

In the face of the funding limitations, the need for a sustainable model was considered to be extremely important. It was generally accepted that sustainability needed to be built into the design of future programs on the basis of empowering the community, or building capacity for the community. It was believed that if the community has the required resources and the right awareness and attitudes, it will continue to build on the outcomes of the programs beyond the provision of funding.

\subsubsection{Non-inclusive Delivery Design and Approach}

Although the community-based approach received favourable feedback from the stakeholders, it was not without challenges. A number of concerns, such as the exclusion of schools as target cohorts, were observed to be a weakness of the programs. It was felt by both young participants and key stakeholders that the main target population of the programs could be easily engaged through working in partnership with local schools. The following comment is cited to illustrate this point.

Some of the working in school was excluding as they were already funded to do that in a different way. It is fairly challenging to reach young people other than in schools, at the age you want to get them before they start having sex really. (Health care provider 3 )

\subsubsection{Biased Target Population}

An additional concern was related to the perceived primary target group of the programs. There was a greater focus on female teenagers. Whilst it was generally accepted by the stakeholders that female teenagers bore the brunt of dealing with an unplanned pregnancy and they generally took more responsibility for birth control or safe sex, there was a sense that there should be a more balanced approach in targeting young men as well as young women. "By its nature it is going to touch women more as they bear the consequence of pregnancy." (LAG10). For this reason, a great effort had been made to engage female teenagers in the programs while male teenagers were not targeted to an equal extent. This was identified as a weakness in program design and delivery because both sexes were believed to play an important role in sexual health.

\subsubsection{Limited Promotional Activities}

Although most of the program activities attracted high levels of community involvement and support, there were marginalised population groups in the community who were not involved, and who were unaware of what was going on in the community. Whilst it can be argued that some groups in the community may choose to disengage from mainstream activities, it is vital that the programs seek out those communities and implement strategies that promote and provide an opportunity for participation should these groups wish to engage in program activities. To help future programs reach out to more community members, stakeholders suggested better targeted promotional or advertising channels appropriate to the target group, such as posters, social media, or local papers.

\subsection{Limitations of study}

A limitation of the program evaluation was the difficulty in recruiting young people to provide extensive feedback regarding the program. As such, a higher number of young informants, particularly male informants, would have provided a greater richness of data and increased the reliability of the findings. It is manifest that trust and respect of young participants remains pivotal to securing their participation in the future evaluation. In addition, both 
quantitative and qualitative data collection methods may be more beneficial in future evaluations, particularly if incorporated into the use of social media.

An additional limitation of the study and the overall program was the inability to provide a comparison in the pre and post outcomes of the program over a longer period. This was largely due to the limited timeframe to undertake the study. It is recommended that a more longitudinal or repeated outcome evaluation study be undertaken to better evaluate the long term benefits of the Teenage Pregnancy Program both within the community and among the teenage population in these rural areas.

The intention of the study was to uncover and highlight the perceptions of community change through a sexual health program, where the programs were based on reliable and validated research. However, there is the potential for future research opportunities to contrast and compare the long term outcomes of the Teenage Pregnancy Program with other programs that have been evaluated for their effectiveness, impact and efficacy.

\section{Discussion}

It can be concluded that the Teenage Pregnancy Programs in the Derwent Valley and the North West region have somewhat influenced community change. Particularly, they have effected a change in the perspective, attitudes and behaviours regarding sexual intimacy and sexual health of some youths in these areas. Those young participants who were interviewed praised the ability of the programs to provide a support network where communication, trust and understanding were established. These links are anticipated to be sustainable beyond the life of the project funding and as such, the teenage pregnancy programs have contributed to the larger goal of social inclusion and are observed as a positive outcome.

The evaluation of the two programs showed that there were six key elements that were shown to successful in delivering the multi-component community-based approaches to sexual health in rural areas, as shown in Table 1.

Table 1. Key elements of multi-component community-based approach

\begin{tabular}{cc}
\hline Elements & Deliverables \\
\hline $\begin{array}{c}\text { Accessibility and } \\
\text { flexibility of } \\
\text { management and } \\
\text { coordination } \\
\begin{array}{c}\text { Proactive facilitators and } \\
\text { coordinators }\end{array}\end{array}$ & $\begin{array}{c}\text { Local stakeholders and youth shaping and } \\
\text { refining programs as required. }\end{array}$ \\
$\begin{array}{c}\text { To actively inspire, involve and connect } \\
\text { individuals, stakeholder and communities. } \\
\text { Information developed to meet the needs } \\
\text { and content }\end{array}$ & $\begin{array}{c}\text { of, and match characteristics of the local } \\
\text { area. }\end{array}$ \\
$\begin{array}{c}\text { Collaboration of } \\
\text { different organisations } \\
\text { Community }\end{array}$ & $\begin{array}{c}\text { Diversity introducing innovative program } \\
\text { delivery. }\end{array}$ \\
$\begin{array}{c}\text { involvement and support } \\
\text { Evidence-based and } \\
\text { need-based approach }\end{array}$ & $\begin{array}{c}\text { High level of community involvement and } \\
\text { community support required. } \\
\text { Addressing the real needs of the } \\
\text { community through local evidence. }\end{array}$ \\
\hline
\end{tabular}

On this basis, it is believed that the Teenage Pregnancy Programs have, in part, contributed to the larger goal of social inclusion, which although not part of the identified scope of the programs, is seen as a positive outcome from the activities. In addition, the communication and support enabled by these networks is also expected to bring about positive changes in attitudes and behaviours among the young people involved.

The local coordinators were seen as being very approachable which is particularly vital when discussing such sensitive issues as sexuality, fertility and contraception. For example, research recently conducted in Tasmania about teenage pregnancy found that "All the young parents highlighted their sense of being judged and feeling a stigma when transacting within the community." [40] Once trust is established, young parents are less hesitant to turn to these health professionals when they are in need of support. It is this sense of trust without judgement which enables young people to access appropriate support and information concerning sexual health, to debunk myths and empower teenagers to make informed choices about their behaviours and attitudes. [11] This finding underlies the vital role that local coordinators play in community-based initiatives.

In addition to the key role of the coordinator, another strength of the programs was shown to be that they combined strategies from a number of prevention and intervention frameworks outlined by Brindis and colleagues [7] and Fullerton. [12] These frameworks focus on a holistic approach to promoting positive sexual health and preventing pregnancy and STIs.

Collaboration between various community groups and organisations was an additional strength of the programs. The merging of different expertise, experiences and perspectives assisted with the program implementation and enabled the programs to embed local knowledge and culture into the delivery of activities. This is considered a sensible choice because the complexity of the issue requires a multi-disciplinary and cross-sectoral group of community members and organisations to facilitate the recruitment and involvement of the young people in the community and enables the exchange of ideas and resources. $[1,7,12,26]$

As teenagers are more likely to be influenced by their peers than adults, particularly when relating to the sensitive issue of sexual health, peer education is an important part of the Teenage Pregnancy Programs. $[5,6]$ This aligns with a finding by the Northern Early Year Group and Uniting Care Tasmania, whereby "sex education at school and conversations with parents is unlikely to be a preferred source of information for this age group." [40] The young participants in this earlier study also regarded peers and the internet as their primary source of information, support and advice about relationships and contraception. Similarly, Stephenson and colleagues [6] found that peer-led sex education might have led to fewer teenage births and was popular with pupils.

It was noted that participation in program activities was primarily by female teenagers and is not uncommon. In his 
review of research on teenage pregnancy, Fullerton [12] noted that such programs are "historically aimed at the needs of women" and thus suggested more inclusive access for and recognition of the needs of young men. While both sexes play an important role in sexual health, and should equally benefit from such sexual health educational programs, models of delivery that is based on accessing a non-biased and more inclusive target population, such as school populations, should be a legitimate approach.

It was suggested that the exclusion of schools from the programs may have acted as an impediment to the programs fully achieving their stated goals. The school environment was viewed as a means to engage with many more teenagers in an environment that may facilitate greater sexual health education. In addition, it can capture a greater proportion of the male population and provide a platform for a more rigorous evaluation of programs and the change within the target population brought about by program implementation. [1, 4] However, as outlined previously, sex education within the school environment is not always a preferred source of information for young people. [40]

\section{Recommendations}

On the basis of the findings, a number of recommendations are presented with a view to increasing the effectiveness and impact of similar sexual health educational programs in the future. These recommendations include having a stronger emphasis on building sustainability into the program design on the basis of community involvement, community empowerment, community capacity building and the development of interpersonal and communication skills. In addition there is the need for greater involvement of young people in all phases of program planning and evaluation; the application of models of promotion and delivery which equally target both young women and young men. More direct and extensive engagement with local schools and in particular the exploration of ways in which programs may complement existing school sexual health programs would add values to the research as would greater funding for sexual health programs that are multi-dimensional and focus on education, attitudes and behaviour. Lastly, there needs to be a greater adoption of more accurate and reliable measurements of community change and the instigation of repeated outcome evaluation studies..

\section{Conclusions}

The aim of the study was to examine the perceptions of community change in attitudes and behaviours and changes in youth awareness about sexual health from the Teenage Pregnancy Programs that sought to address the issue of high teenage pregnancy rates in two regional areas of Tasmania, through the engagement of local community groups and clinical services. Overall, the programs were considered to be well managed and delivered, which was evidenced by the generally positive feedback from both the young people and other stakeholders. The evaluation provides valuable knowledge regarding the processes and outcomes of the program which may have application in future community based sexual health programs. The opportunity for input by the program recipients regarding the design, delivery and evaluation of the programs must not be undervalued as a means to build the capacity and relevance of the programs to the local community.

The issue of funding support and program sustainability remained a focus for the various stakeholder groups. To address social issues such as high rates of unplanned pregnancy amongst teenagers in small regional communities requires a sustained effort which is reliant on sufficient funding and resourcing. Whilst the program effectiveness and impact in terms of community change, such as increased awareness about sexual health, has been perceivably positive, it is difficult to assess the real impact of the programs in terms of behavioural changes, such as reduced teenage pregnancy, over the duration of the life cycle of the programs. It would be practical to undertake longer term studies after the closure of the programs for a more realistic assessment of their impact on community change. Although this study is a relatively small one and the programs evaluated had not been operating for very long, their evaluation gives an insight into what works in these types of communities, how to embed a program into a community and also what the community thinks will work.

\section{Appendix 1}

\section{Questions for focus group and interview participants}

\section{Questions for focus group}

1. What is your general impression about the program/activities/training that you received from the Family Planning Tasmania?

2. What are its strengths?

3. What are its weaknesses? What are specific things about the program/activities/training which need to be improved?

4. What is your view about the content of the program/activities/training that you attended? To what extent do you think the program/training/activities can improve your knowledge/awareness regarding teenage pregnancy prevention?

5. To what extent do you think the program/training/activities can change your attitudes or beliefs towards teenage pregnancy prevention?

6. What is your view about the format of the program/activities/training?

7. What do you think about the function of the program/activities/training as a method to reduce 
teenage pregnancy in your region?

8. How important do you think the program/activities/training is to the clinical procedure at your medical practice?

9. Are there any other comments you wish to make about the program/activities/training by the Family Planning Tasmania?

\section{Questions for interview participants}

1. What is your general impression about the services/programs/activities that you received from the Family Planning Tasmania at your local doctor health clinics?

2. Were the services/programs/activities better or worse than your expectation? Can you please provide more information on this matter?

3. What is your view about the content of the services/programs/activities that you attended? To what extent do you think the services/programs /activities can improve your knowledge/awareness regarding sexuality and sexual health?

4. To what extent do you think the services/programs /activities can change your attitudes or beliefs towards sexuality and sexual health?

5. To what extent do you think the services/programs /activities can change your behaviours regarding sexuality and sexual health?

6. What is your view about the process of these services/programs/activities?

7. What do you think about the communication (pamphlets, advice, service, information) of the services/programs/activities as a method to reduce teenage pregnancy in your region?

8. How important do you think the services/programs/activities at your local doctor health clinics are to young people in local community?

9. Are there any other comments you wish to make about the services/programs/activities conducted by the Family Planning Tasmania?

\section{REFERENCES}

[1] Frost JJ, Forrest JD. Understanding the Impact of Effective Teenage Pregnancy Prevention Programs. Family Planning Perspectives. 1995;27(5):188-95.

[2] Best Start. Teenage pregnancy prevention. Ontario: Ontario's Maternal, Newborn and Early Child Development Resource Centre and the Sex Information and Education Council of Canada, 2007.

[3] Cheesbrough S, Ingham R, Massey D. A review of the international evidence on preventing and reducing teenage conceptions: the United States, Canada, Australia and New Zealand. Health Development Agency, 2002.

[4] Kirby D, Short L, Collins J, Rugg D, Kolbe L, Howard M, et al. School-based programs to reduce sexual risk behaviors: a review of effectiveness. Public health reports. 1994;109(3):339.

[5] Warunee F, Saowaluck S, Kangwan F, Natthakarn S. Effectiveness of a youth-led educational program on sexual and reproductive health for Thai early adolescents. Pacific Rim International Journal of Nursing Research. 2011;15(2):81-96.

[6] Stephenson J, Strange V, Allen E, Copas A, Johnson A, Bonell $\mathrm{C}$, et al. The long-term effects of a peer-led sex education programme (RIPPLE): A cluster randomised trial in schools in England. PLoS Med. 2008(5):11.

[7] Brindis CD, Sattley D, Mamo L. From Theory to Action: Frameworks for Implementing Community-Wide Adolescent Pregnancy Prevention Strategies. San Francisco, CA: University of California, San Francisco, Bixby Center for Reproductive Health Research \& Policy, Department of Obstetrics, Gynecology \& Reproductive Sciences, and the Institute for Health Policy Studies, 2005.

[8] Darroch JE, Singh S, Frost JJ. Differences in Teenage Pregnancy Rates among Five Developed Countries: The Roles of Sexual Activity and Contraceptive Use. Family Planning Perspectives. 2001;33(6):244-81.

[9] Buston K, Williamson L, Hart G. Young women under 16 years with experience of sexual intercourse: who becomes pregnant? Journal of epidemiology and community health. 2007;61(3):221-5.

[10] Panchaud C, Singh S, Feivelson D, Darroch JE. Sexually transmitted diseases among adolescents in developed countries. Family Planning Perspectives. 2000;32(1):24-45.

[11] Tripp J, Viner R. ABC of adolescence: Sexual health, contraception, and teenage pregnancy. British Medical Journal. 2005;330(7491):590.

[12] Fullerton D. Promoting Positive Adolescent Sexual Health \& Preventing Teenage Pregnancy - A Review of Recent Effectiveness Research. Crisis Pregnancy Agency, 2004.

[13] Wight D, Fullerton D. A Review of Interventions With Parents to Promote the Sexual Health of Their Children. Journal of Adolescent Health. 2013;52(1):4-27.

[14] Paul G, Bell C, Fitzpatrick A, Smith SM. 'The real deal': A feasibility study of peer-led sex education for early school leavers. The European Journal of Contraception and Reproductive Health Care. 2010;15(5):343-56.

[15] Tolli MV. Effectiveness of peer education interventions for HIV prevention, adolescent pregnancy prevention and sexual health promotion for young people: a systematic review of European studies. Health Education Research. 2012;27(5):904-13.

[16] Chin HB, Sipe TA, Elder R, Mercer SL, Chattopadhyay SK, Jacob V, et al. The Effectiveness of Group-Based Comprehensive Risk-Reduction and Abstinence Education Interventions to Prevent or Reduce the Risk of Adolescent Pregnancy, Human Immunodeficiency Virus, and Sexually Transmitted Infections: Two Systematic Reviews for the Guide to Community Preventive Services. American Journal of Preventive Medicine. 2012;42(3):272-94.

[17] Goesling B, Colman S, Trenholm C, Terzian M, Moore K. Programs to Reduce Teen Pregnancy, Sexually Transmitted 
Infections, and Associated Sexual Risk Behaviors: A Systematic Review. Journal of Adolescent Health. 2014;54(5):499-507.

[18] Catalano RF, Fagan AA, Gavin LE, Greenberg MT, Irwin Jr CE, Ross DA, et al. Worldwide application of prevention science in adolescent health. The Lancet. 2012;379(9826):1653-64.

[19] Nation M, Crusto C, Wandersman A, Kumpfer KL, Seybolt D, Morrissey-Kane E, et al. What works in prevention: Principles of effective prevention programs. American Psychologist. 2003;58(6-7):449.

[20] Kirby DB, Laris BA, Rolleri LA. Sex and HIV Education Programs: Their Impact on Sexual Behaviors of Young People Throughout the World. Journal of Adolescent Health. 2007;40(3):206-17

[21] Santelli J, Ott MA, Lyon M, Rogers J, Summers D, Schleifer R. Abstinence and abstinence-only education: A review of U.S. policies and programs. Journal of Adolescent Health. 2006;38(1):72-81.

[22] Kirby D, Short L, Collins J, Rugg D, Kolbe L, Howard M, et al. School-based programs to reduce sexual risk behaviors: a review of effectiveness. Public Health Reports. 1994;109(3):339-60.

[23] Kirby D. Effective approaches to reducing adolescent unprotected sex, pregnancy, and childbearing. The Journal of Sex Research. 2002;39(1):51-7.

[24] Philliber S, Kaye JW, Herrling S, West E. Preventing pregnancy and improving health care access among teenagers: An evaluation of the Children's Aid Society-Carrera Program. Perspectives on Sexual and Reproductive Health. 2002;34(5):244-51.

[25] DiCenso A, Guyatt G, Willan A, Griffith L. Interventions to reduce unintended pregnancies among adolescents: systematic review of randomised controlled trials. BMJ 2002;324:1426.

[26] Scher LS, Maynard RA, Stagner M. Interventions intended to reduce pregnancy-related outcomes among adolescents Philadelphia, PA: Smith Richardson Foundation, Hewlett Foundation, and American Institutes for Research, 2002.

[27] Makin J, Butler S, editors. "Tell Me About It" - a Community-based Project to Reduce the Rate of Teen Pregnancy in Wagga Wagga. 6th National Rural Health Conference; 2001 4-7 March; Canberra, Australian Capital Territory.

[28] Australian Bureau of Statistics. National Regional Profile 2006-2010 Canberra: Australian Bureau of Statistics; 2012 [updated 2 November 2011]. Available from: http://www.ausstats.abs.gov.au/ausstats/nrpmaps.nsf/NEW+ GmapPages/national+regional+profile?opendocument.
[29] Australian Bureau of Statistics. Births Australia 2011 Australian Births per 1000 of estimated resident $15-19$ years population. Canberra: ABS, 2010 Contract No.: Cat 3301.0.

[30] DoHA. Australia's notifiable diseases status, 2009: Annual report of the National Notifiable Diseases Surveillance System - Sexually transmissable diseases Canberra: Department of Health and Ageing; 2011 [cited 201325 July]. Available from:http://www.health.gov.au/internet/main/publ ishing.nsf/Content/cda-cdi3502-pdf-cnt.htm/\$FILE/cdi3502a .pdf.

[31] Derwent Valley Council. Derwent Valley Council area Community profile 2011 [cited 201310 July]. Available from: http://profile.id.com.au/derwent-valley/service-age-groups.

[32] Australian Bureau of Statistics. 2033.0.55.001 - Census of Population and Housing: Socio-Economic Indexes for Areas (SEIFA), Australia, 2011 Canberra: Australian Bureau of Statistics; 2013 [cited 201328 July]. Available from: http://www.abs.gov.au/AUSSTATS/abs@.nsf/DetailsPage/2 033.0.55.0012011? OpenDocument.

[33] McDonald L, Billingham S, Conrad T, Morgan A, O N, Payton E. Families and schools together (FAST): Integrating community development with clinical strategies. Families in Society: The Journal of Contemporary Social Services. 1997;78(2):140-55.

[34] Coote S. Families and schools together (FAST). Reducing Criminality: Partnerships and Best Practice; Perth, WA: FAST International, Australasia \& South East Asia; 2000. p. 31 July - 1 August.

[35] Stone N, Ingham R. Factors affecting British teenagers' contraceptive use at first intercourse: The importance of partner communication Perspectives on Sexual and Reproductive Health. 2002;34(4):191-7.

[36] Bernard HR. Social research methods: Qualitative and quantitative approaches. 4th ed. Thousand Oaks: Sage Publications; 2000.

[37] Davis P, Scott A. Health research sampling methods. In: Saks M, Allsop J, editors. Researching health: qualitative, quantitative and mixed methods. London: Sage Publications; 2007. p. 155-73.

[38] Liamputtong P, Ezzy D. Qualitative Research Methods. 2nd ed. South Melbourne: Oxford University Press; 2005.

[39] Graneheim UH, Lundman B. Qualitative content analysis in nursing research: concepts, procedures and measures to achieve trustworthiness. Nurse education today. 2004;24(2):105-12.

[40] Northern Early Year Group, UnitingCare Tasmania. Teenage pregnancy research report. Tasmania: Northern Early Year Group and UnitingCare Tasmania, 2013. 